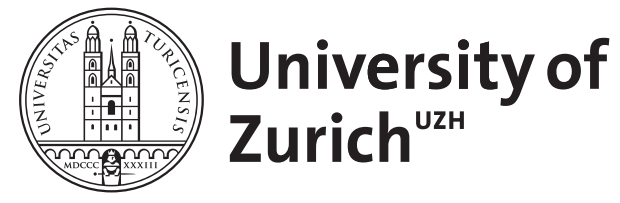

Zurich Open Repository and Archive

University of Zurich

University Library

Strickhofstrasse 39

CH-8057 Zurich

www.zora.uzh.ch

Year: 2001

\title{
Answer to Photo Quiz
}

Mackowiak, P A ; Zinkernagel, A S ; Schaffner, A ; Himmelmann, A

DOI: https://doi.org/10.1086/319768

Posted at the Zurich Open Repository and Archive, University of Zurich

ZORA URL: https://doi.org/10.5167/uzh-153975

Journal Article

Published Version

Originally published at:

Mackowiak, P A; Zinkernagel, A S; Schaffner, A; Himmelmann, A (2001). Answer to Photo Quiz. Clinical Infectious Diseases, 32(8):1233-1234.

DOI: https://doi.org/10.1086/319768 
Philip A. Mackowiak, Section Editor

\section{(See page 1188 for Photo Quiz)}
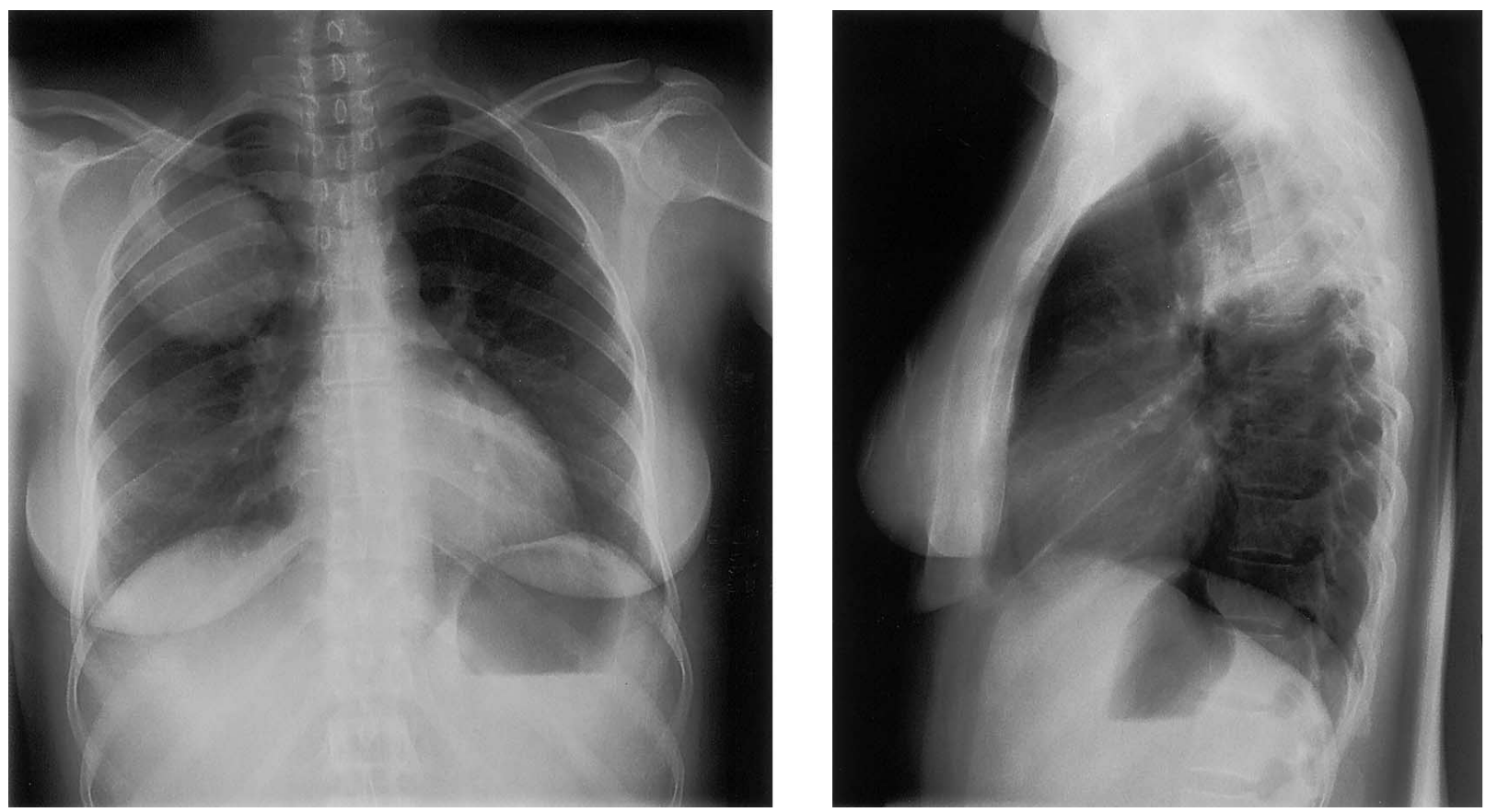

Figure 1. Posteranterior (left) and lateral (right) chest radiographs obtained at presentation show a well-defined round mass in the right upper lobe

Diagnosis: round pneumonia due to Streptococcus pneumoniae.

Fewer than $1 \%$ of cases of pneumonia manifest as pulmonary round lesions. Because a round lesion is an early manifestation of the disease, a history of cough or fever may be absent at the time of presentation [1]. Early in the course of infection, the inflammatory process is predominantly confined to the alveolar space. It spreads by direct extension through the interalveolar channels (the pores of Kohn and the channels of Lambert). This results in a lesion with a nonsegmental distribution and smooth borders. Later, with centrifugal and peribronchial spread, the pneumonia lesion becomes segmental or lobar, and the typical appearance is seen on a radiograph $[2,3]$.

The pathways of collateral ventilation (the pores of Kohn) are poorly developed in children. Children also have more

Reprints or correspondence: Annelies S. Zinkernagel, Department of Internal Medicine, University Hospital Zurich, Rämistrasse 100, 8091 Zurich, Switzerland (annelies.zinkernagel @dim.usz.ch).

Clinical Infectious Diseases 2001;32:1233-4

(C) 2001 by the Infectious Diseases Society of America. All rights reserved. $1058-4838 / 2001 / 3208-0018 \$ 03.00$ closely apposed connective tissue septae and smaller alveoli than adults do. These factors work together to produce more-compact confluent areas of pulmonary consolidation, without the softer margins that are evident in the typical infiltrates seen in adults [4]. They also result in a slower progression of disease and increase the chance of detecting round pneumonia. Therefore, round pneumonia is more often seen in children than in adults.

The organism that most frequently causes round pneumonia has been found to be Streptococcus pneumoniae, followed, in descending order of frequency, by Klebsiella pneumoniae, Haemophilus influenzae, Coxiella burnetti, and Mycobacterium tuberculosis. Fungal infections, hydatid cysts, and lung abscesses may have a similar appearance on chest radiographs [5]. Although malignant lesions are the most common cause of pulmonary round lesions in adults, one should consider infectious processes, malformations, and round atelectasis, as well as benign tumors, in any differential diagnosis of pulmonary mass lesions. 


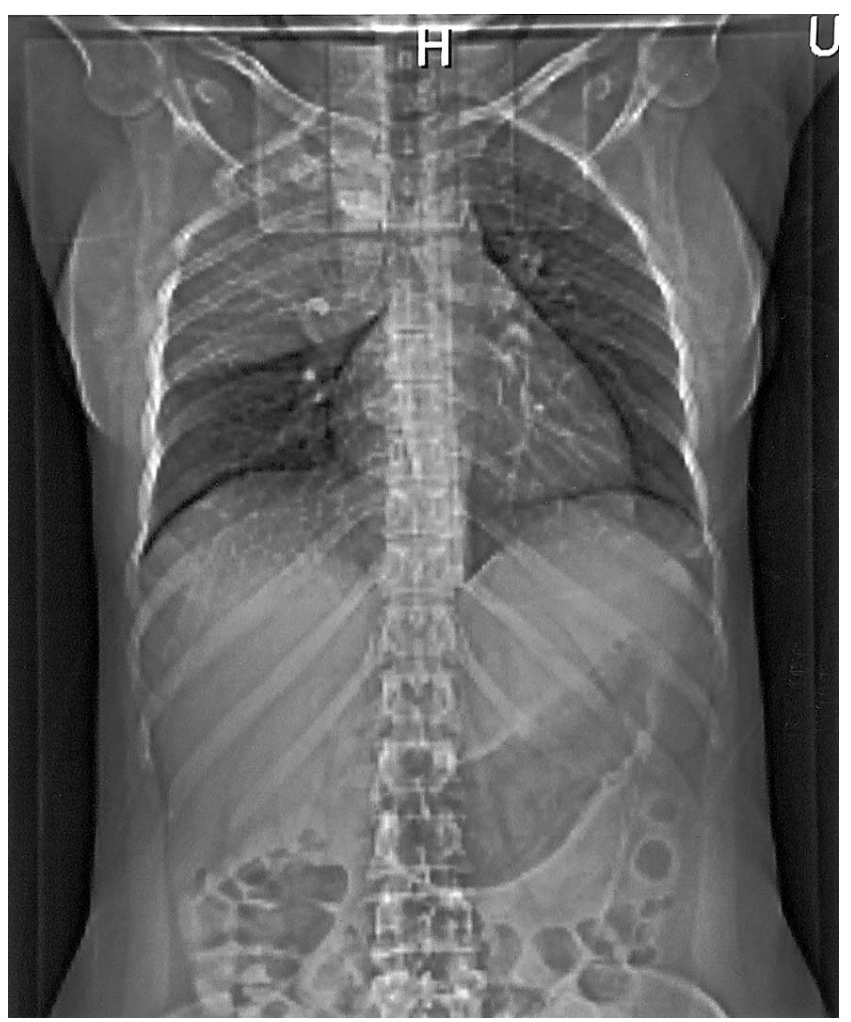

Figure 2. Posteroanterior chest radiograph obtained $24 \mathrm{~h}$ after admission shows an infiltrate in the region of the apicoposterior segment of the upper lobe, as seen in a classical pneumonia.
Our patient had pneumococcal pneumonia with sepsis and oliguria (figure 1). Cultures of blood samples yielded S. pneumoniae. She was successfully treated with amoxicillin for 10 days and with aggressive volume resuscitation because of hypotension with prerenal azotemia. A chest radiograph obtained $24 \mathrm{~h}$ after admission showed classic lobar pneumonia (figure 2).

Annelies S. Zinkernagel, Andreas Schaffner, and Andreas Himmelmann Department of Internal Medicine, University Hospital Zurich, Zurich

\section{References}

1. Wagner AL, Szabunio M, Hazlett KS, Wagner SG. Radiologic manifestations of round pneumonia in adults. Am J Roentgenol 1998; 170 : 723-6.

2. Pandya K, Tuchschmidt J, Gordonson J, Boylen CT. Mass lesion in an intravenous drug user. West J Med 1989; 150:95-6.

3. Soubani AO, Epstein SK. Life-threatening round pneumonia. Am J Emerg Med 1996; 14:189-91.

4. McLennan MK. Radiology rounds. Can Fam Physician 1998;44:757-9.

5. Torres $\mathrm{H}$, Noronha PA. A healthy infant with a round pneumonia. Hosp Pract 1984; 19:57-61. 